\title{
Model-based analysis of the viability of concentrating solar power plants
}

\author{
Martin János Mayer \\ Department of Energy Engineering \\ Budapest University of Technology and Economics \\ Bertalan Lajos u. 4-6. D bldg. 2nd floor, H-1111 Budapest (Hungary) \\ Phone/Fax number: +36303430825, e-mail: mayer.martinj@gmail.com
}

\begin{abstract}
This paper presents an assessment of the effect of thermal energy storage and combined heat and power production on the profitability of concentrating solar power (CSP) plants. Nowadays CSP plants produce electricity for a higher cost than commercial photovoltaic (PV) systems, therefore the mentioned opportunities enabled by the intermediate heat production have a key role in the economic viability of the technology. Models were established to describe the operation of both the parabolic trough and solar power tower systems. A Matlab simulation program was created based on the models in order to support the optimal design of these plants and perform annual energy production estimations based on meteorological databases. Thermal energy storage is a relatively cheap method even for long time storage, and it not only increases the capacity factor, but also improves the average efficiency of the plant. Furthermore a storage also improves the availability and dispatchability of the plant, which is a very important factor in an energy system with high renewable share. Cogeneration is also feasible in CSP plants, the only difficulty here is to find a heat demand coinciding with the production.
\end{abstract}

\section{Key words}

Solar energy, concentrating solar power, simulation, storage, combined heat and power

\section{Introduction}

Concentrating solar power (CSP) plants are used for indirect electricity production, where the solar radiation is converted to heat which is used for power production by a thermodynamic cycle. Solar thermal power plants only represent a small portion in the global electricity production, but the dynamic increase of their installed capacity in the last several years predicts their increasing importance in the future. CSP is an expensive technology, the levelized cost of electriticy (LCOE) production is significantly higher than the costs of conventional energy generation methods [1]. The photovoltaic (PV) systems, which convert the radiation directly into electricity, are also much cheaper than CSP if we only consider revenues coming from the sold electricity. In the other hand, the intermediate heat production of the indirect energy conversion in CSP plants enables several opportunities, like thermal energy storage (TES) and combined heat and power (CHP) production, which are not available in PV systems. The integration of these options into CSP plants can be a good way to improve their economical profitability despite their initially higher costs.

Concentrating solar power plants are generally classified according to solar field used for the heat production. The two most important types, according to their total worldwide installed capacity, are parabolic trough and solar power tower systems. The advantages of the parabolic trough systems are their maturity and modularity, while the main advantage of the solar power tower systems is their higher efficiency coming from a higher heat transfer fluid (HTF) temperature. The electricity is produced by a Rankine-cycle with reheat in both cases [2]. Both CSP plant types were modelled using Matlab in order to describe their detailed operation characteristics, and to perform various simulations and performance estimations. The annual energy production, which is essential in economical payback calculations, was estimated based on a meteorological database. The results were compared with the typical values of PV systems investigated in my previous researches [3]. Similar calculations were made for plants with thermal storage and cogeneration, which have revealed how these possibilities improve the viability of the plant.

\section{Modelling method}

The main goal of the simulation models is to describe the effects of the meteorological conditions on the operation of the mentioned plants. The input data are the most defining meteorological attributes; the solar irradiance and the 
ambient temperature. The most important output data are the generated power, the different efficiencies and the amount of the produced energy. The model consists of three parts, the model of the solar field, the Rankine power block and the thermal energy storage. A simulation program was developed in Matlab, based on the main considerations presented below.

\section{A. Solar field model}

The model of the solar field calculates the amount of heat produced from the solar radiation, based on the meteorological data and the position of the sun. The sun's position, which is necessary for the calculation of the incidence angle, was computed based on the exact date and time using basic astronomical relationships [4]. In case of parabolic trough collectors the incidence angle depends on the alignment of the collectors and it is same for the whole solar field due to its modularity - it consists of numerous solar collector assemblies with the same parameters and properties. In contrast, in case of a solar tower system the incidence angle is different for all heliostats, since it depends on the distance and direction between the central tower and the given heliostat. The cell-wise method was implemented in the model, where the solar field is divided into concentric cells identified by a radial and an angular coordinate, and the parameters are considered to be the same in each cell [5].

The efficiency of the heat production was divided into two parts, the solar effectiveness, which only depends on the position of the sun, and the collector efficiency, which is affected by the irradiance and the temperature. The most significant part of the solar effectiveness is the cosine effectiveness calculated as the cosine of the incidence angle. Furthermore it takes into account the shading losses, the incidence angle modifier and the end loss ratio of parabolic trough collectors. The collector efficiency contains the optical and heat losses. The optical losses are caused by the non-ideal optical properties of the mirror and the receiver, and they have a constant ratio to the radiant energy. In solar tower systems the attenuation of the radiation between the heliostat and the receiver is also a considerable source of optical losses. The heat losses depend on the temperature difference between the heat transfer fluid and the ambient and have an increasing proportion with decreasing irradiance. The amount of the produced thermal power is the product of the total mirror area, the direct normal irradiance (DNI), the solar effectiveness and the collector efficiency.

\section{B. Rankine power block model}

The schematic of the Rankine power block considered in the model can be seen in Figure 1. The Rankine-cycle model is based on fundamental thermodynamic and energy balance equations. The relationship between the different state variables is computed with the FluidProp solver, which contains a large variety of fluids and uses the latest physical models in the calculations. The losses occurring in the turbines and pumps are taken into account using internal efficiencies. Wet cooling towers are typical in CSP plants, therefore a constant temperature difference was set between the condenser and the ambient. The temperature profiles of the heat exchangers are calculated according to the pinch point method, where a minimal temperature difference is set between the temperature profiles of the working fluid and the heat transfer fluid. Pressure drops and heat losses in the pipes and apparatus were neglected.

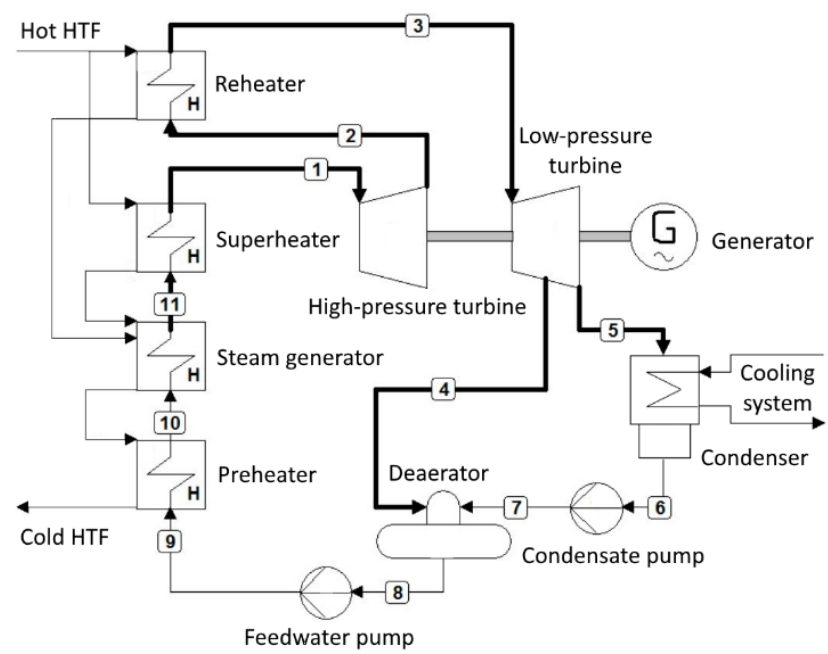

Fig. 1. Schematic of the Rankine power block

The off-design model describes the sliding-pressure partload operation, where the pressures of the evaporator, reheater and deaerator are determined by Stodola's cone law. The deterioration of the turbine and generator efficiency in part-load condition is taken into account with a load-dependent correction factor [6].

\section{Thermal energy storage model}

Long-term thermal energy storage can be achieved in CSP plants using direct or indirect molten salt tanks. The storage size is typically specified in hours, which indicates that how long the power plant can operate at nameplate power using a fully charged storage. Another important design parameter related to the energy storage is the solar multiple (SM), which is the ratio of the heat produced by the solar field and the heat input of the power block under nominal conditions. A higher SM indicates an oversized solar field, where an excess heat production is available to charge the storage. The storage size and the solar multiple always have to be chosen in accordance to each other.

Six different operating state can be distinguished in storage-equipped CSP plants depending on that the heat production, the storage and the power block is operating or not. The storage strategy determines that which operating state is used under the given condition, and the implementation of this strategy is the main task of the thermal energy storage model. According to the strategy chosen for the further examinations the produced heat is primarily used in the power block, only the surplus is stored, while the storage is immediately starting to discharge when the heat production drops below the maximum heat input of the power block. This strategy ensures the maximal utilization of the storage. More sophisticated strategies can also be developed in order to fit the electricity production to a desired schedule or shift the production to the peak hours with a higher electricity price. 
The nowadays typical subsidy system with constant feedin tariffs does not support these strategies, therefore they were not examined in this paper.

\section{Design calculations}

The presented model can be used both for design and performance estimation calculations. The purpose of the design calculation is to determine the total mirror aperture area and nominal values of all important parameters of the desired CSP plant, which data are essential in performance estimation calculations. The nameplate capacity of the examined power plants are $50 \mathrm{MW}_{\mathrm{e}}$. The plant site is near Seville, at the geographic coordinates $37.4^{\circ} \mathrm{N} 5.7^{\circ} \mathrm{W}$. The design time is solar noon at the day of summer solstice and the design conditions are $1000 \mathrm{~W} / \mathrm{m}^{2} \mathrm{DNI}$ and $25^{\circ} \mathrm{C}$ ambient temperature. Two plants were designed of both the parabolic trough collector and solar power tower systems, one with $\mathrm{SM}=1$ and another with $\mathrm{SM}=3$, which latter is appropriate for the application of a large thermal energy storage.

In the first step of the design process the electrical efficiency of the power block was calculated using reasonable parameters based on typical values in practical applications. The amount of the required heat production, which is the basis of the solar field sizing, was determined by the power block efficiency and the solar multiple. In case of the parabolic trough collectors a north-south axis alignment was chosen, since it provides a higher annual effectiveness than the east-west alignment, although it leads to a higher seasonal fluctuation. The heliostat field has central layout around the tower with a sparser placement of mirrors in the outer rings in order to prevent increased shading. The most important results of the design calculations are listed in the Table I.

The solar tower systems have a better power block efficiency due to the higher parameters of the Rankinecycle enabled by the higher heat transfer fluid temperature. The higher power block efficiency is also favourable in the aspect of storage, since less heat has to be stored in order to produce the same amount of electricity. Moreover, as a result of the higher temperature difference between the hot and cold tank, a significantly smaller molten salt mass and tank volume is sufficient in solar tower power plants to ensure the same storage capacity. The efficiency of heat production is constant in parabolic trough systems due to the modular layout of the solar field, therefore both the mirror and land area are proportional to the nameplate power of the plant. In contrast, the heat production efficiency of solar tower systems depends on the size of the heliostat field, which is caused by the higher attenuation losses and less favourable incidence angle for heliostats farther from the tower. This effect limits the size of a solar tower power plant, since its total efficiency decreases with increasing unit sizes. For similar reasons, total land area demand is larger for parabolic trough systems at smaller sizes, but this relation is reversed at larger scales. Nevertheless, the total power plant efficiency is higher for solar tower power plants in all examined cases.

\section{Performance estimation calculations}

The purpose of the performance estimation is to calculate the expected annual energy production of the power plant. The accurate prediction of the annually produced energy of a power plant is essential in economic calculations, since the revenues of the plant are coming from the sold electricity. Furthermore, due to the statistical characteristic and continuous changing of the meteorological conditions the annually summarized or averaged values are much more suitable indicators for the evaluation and comparison of CSP technologies than the nominal ones. The key performance indicators used in the further examination are the annual average efficiency and the capacity factor. Both of them give information about the amount of the produced energy, related to the total radiation energy and the nameplate capacity, respectively. The calculations are based on the Meteonorm 6.1 database, which contains parallel DNI and ambient temperature data for all hours of a typical year [7].

\section{A. Annual energy production}

The optimal size of the thermal energy storage can only be chosen according to the result of annual energy production calculations. In case of small storage tanks the storage gets filled up too quickly and a large part of the produced heat surplus has to be spilled. A larger storage reduces these spillage losses and therefore increases the annual energy production, as an example can be seen in Figure 2, but also raises the investment costs. The optimal storage size can only be determined by a comprehensive economic optimization, in which the extra revenues coming from the higher energy production are compared to the extra investment costs. In absence of reliable cost functions or in case of less specified power plants with generally applicable results an approximation method can also be used. In this way the storage size belonging to the $2.5 \%$ or less spillage loss proportion is chosen as an approximately optimal result. According this method and the simulation results, the optimal storage size is 12 hours for the

Table I. - Main design parameters of different CSP plants with $50 \mathrm{MW}_{\mathrm{e}}$ nameplate capacity

\begin{tabular}{|l|c|c|c|c|c|c|c|}
\hline $\begin{array}{c}\text { Concentrating } \\
\text { solar power plant } \\
\text { type }\end{array}$ & $\begin{array}{c}\text { Solar } \\
\text { multiple }\end{array}$ & $\begin{array}{c}\text { Solar field } \\
\text { thermal power }\end{array}$ & $\begin{array}{c}\text { Total mirror } \\
\text { aperture area }\end{array}$ & $\begin{array}{c}\text { Total occupied } \\
\text { land area }\end{array}$ & $\begin{array}{c}\text { Power block } \\
\text { efficiency }\end{array}$ & $\begin{array}{c}\text { Heat production } \\
\text { efficiency }\end{array}$ & $\begin{array}{c}\text { Total electric } \\
\text { efficiency }\end{array}$ \\
\hline \multirow{2}{*}{$\begin{array}{l}\text { Parabolic trough } \\
\text { system }\end{array}$} & 1 & 147.66 & 241.2 & 0.8 & 33.86 & 61.22 & $\%$ \\
\hline \multirow{2}{*}{$\begin{array}{l}\text { Solar tower } \\
\text { system }\end{array}$} & 3 & 442.97 & 723.5 & 2.3 & 33.86 & 61.22 & 20.73 \\
\cline { 2 - 9 }
\end{tabular}


examined parabolic trough power plant and 10 hours for the solar power tower system.

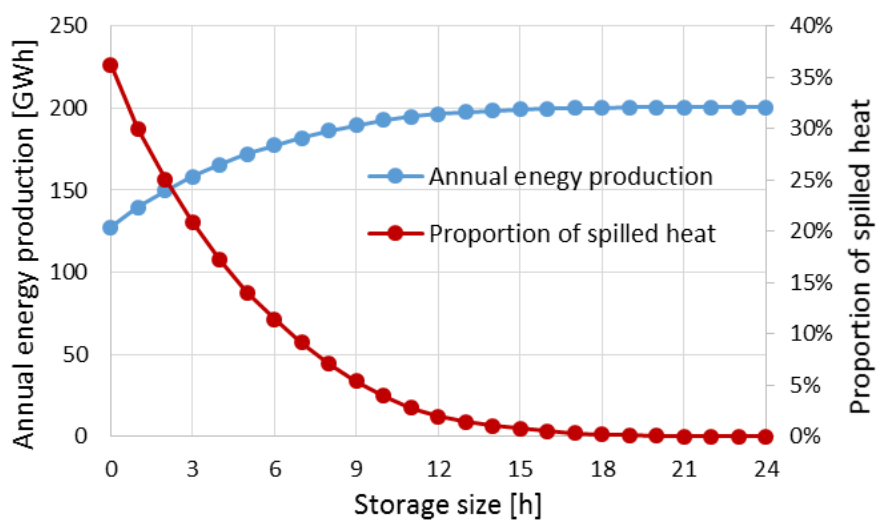

Fig. 2. Annual energy production as a function of the storage size for the $\mathrm{SM}=3$ parabolic trough system

The results of the performance estimation calculations for the four examined CSP plants and a typical PV system can be seen in the Table II [3]. The capacity factor of the parabolic trough and solar tower systems are nearly the same, which indicates a similar annual energy production. The annual average efficiency is smaller than the nominal one in all cases as a consequence of the decreased efficiency under part load conditions. The efficiency itself only influences the required mirror area for a given nominal power, but the ratio of the annual and nominal efficiencies describe the deterioration of the power plants' performance due to the non-optimal weather conditions.

Table II. - Annual average efficiency and capacity factor of the examined solar power plants

\begin{tabular}{|l|l|c|c|c|}
\hline \multicolumn{2}{|c|}{$\begin{array}{l}\text { Solar power plant type and } \\
\text { thermal energy storage size }\end{array}$} & $\begin{array}{c}\text { Nominal } \\
\text { electric } \\
\text { efficiency }\end{array}$ & $\begin{array}{c}\text { Annual } \\
\text { electric } \\
\text { efficiency }\end{array}$ & $\begin{array}{c}\text { Capacity } \\
\text { factor }\end{array}$ \\
\cline { 3 - 5 } & $\%$ & $\%$ & $\%$ \\
\hline $\begin{array}{l}\text { Parabolic } \\
\text { trough system }\end{array}$ & No storage & 20.73 & 12.98 & 13.56 \\
\cline { 2 - 5 } & 12 h storage & 20.73 & 14.32 & 44.90 \\
\hline \multirow{2}{*}{$\begin{array}{l}\text { Solar tower } \\
\text { system }\end{array}$} & No storage & 24.02 & 15.05 & 13.58 \\
\cline { 2 - 5 } & 10 h storage & 21.18 & 15.65 & 48.02 \\
\hline \multicolumn{2}{|l|}{ Photovoltaic system } & 15.20 & 12.84 & 19.41 \\
\hline
\end{tabular}

The capacity factor of the PV system is higher than the value for the CSP plants without storage, which means a higher annual electricity production. A very important difference is that the CSP plant utilize the direct normal irradiation, while the PV systems use the global irradiation on the tilted module surface, which are fundamentally different, $1898 \mathrm{kWh} /\left(\mathrm{m}^{2} \mathrm{a}\right)$ and $2014 \mathrm{kWh} /\left(\mathrm{m}^{2} \mathrm{a}\right)$ respectively according to the Meteonorm database. The causes of the higher PV capacity factor is the higher irradiation and the better part-load operation, which is indicated by the smaller difference between the nominal and annual efficiencies. The specific investment costs are around 3000-5000 EUR/kWh for a CSP plant without storage and 1000-1500 EUR/kWh for a PV system [1]. The much lower investment costs, in addition to the higher energy production results in a significantly lower LCOE for the PV technology.
The integration of the thermal energy storage into the power plant more than triples the capacity factor and also increases the annual average efficiency. The rise of the capacity factor is a consequence of the increased size of the solar field according to the $\mathrm{SM}=3$ design parameter, but the higher efficiency indicates the better utilization of the given solar resource. The thermal energy storage enables the power block to run under nominal conditions during a considerable part of the year, which is the main reason of the improved annual efficiency. The operation of the thermal energy storage is illustrated in Figure 3 with the produced heat and the heat input of the storage and the power block as a function of time. The specific investment cost of CSP plants with storage is around 6000-8000 EUR/kWh, which leads to a LCOE lower than the value for the CSP plants without storage, but still higher than the result for PV systems. More detailed economic calculations were not performed due to the unreliability and larger variations of the CSP cost functions.

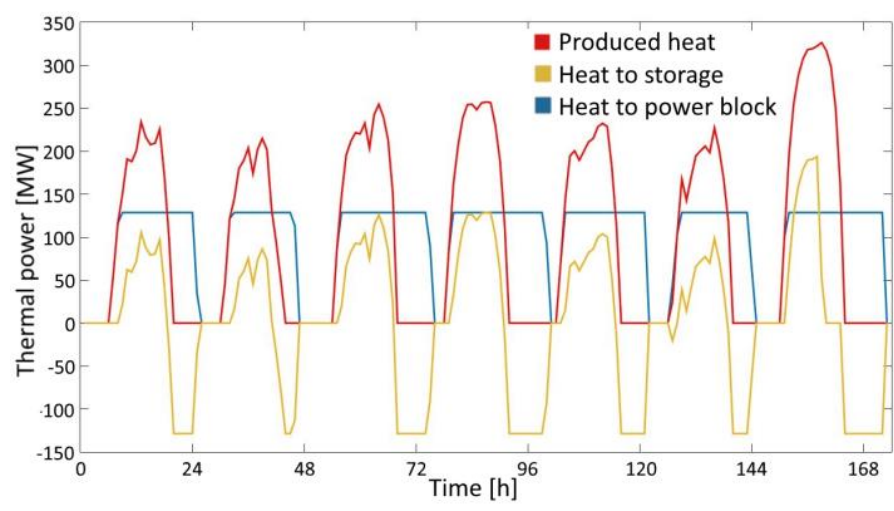

Fig. 3. Illustration of the operation of the thermal energy storage

Despite the higher electricity production cost, the opportunity of a relatively cheap and long-term storage is a great advantage of the CSP plants over the PV technology. The storage improves the availability of the power plant and makes it a dispatchable energy producing unit. Dispatchability is a key feature on a competitive energy market, where much higher prices are available provided that the electricity production can follow a previously specified schedule. A dispatchable power plant takes part in the frequency control of the grid, especially in the secondary control, which can result in considerable extra revenues for the plant. The control capability is expected to have an even bigger importance in energy systems with increasing penetration of weather dependent PV and wind energy sources in the future. However, the constant feed-in tariff offered by the nowadays prevalent renewable energy subsidy concepts suppresses the benefits coming from the energy storage, which can be the main reason behind the still moderate expansion of the CSP market.

\section{B. Combined heat and power production}

Similarly to the conventional power plants equipped with Rankine power block, the CSP plant also have the opportunity to run in CHP mode by applying a back pressure turbine in order to utilize the heat rejected by the Rankine-cycle. A higher temperature of exhaust steam enables wider and more effective utilization of the 
produced heat, but also decreases the electrical efficiency of the power block. As a trade-off, 1 bar back pressure was considered in the calculations, which results in a $100{ }^{\circ} \mathrm{C}$ saturated steam exhaust. This temperature is sufficient for typical district heating purposes and many industrial processes. The results of the annual heat and power production calculations are summarized in the Table III. The amount of the total radiation energy is the same in all rows of the table, therefore the annual average efficiencies are proportional to the produced electricity and heat. The electrical efficiency decreased by around 3 percentage points is all cases as a result of cogeneration, which means an $18-25 \%$ decrease in the electricity generation. On the other hand, a heat production efficiency of about $30 \%$ is achieved, which indicates that 10 units of heat can be produced at the cost of one unit decrease in electrical energy output.

Table III. - Annual average efficiency of the examined solar power plants in case of electricity production and cogeneration

\begin{tabular}{|c|c|c|c|c|}
\hline \multirow{3}{*}{\multicolumn{2}{|c|}{$\begin{array}{l}\text { Solar power plant type and } \\
\text { thermal energy storage size }\end{array}$}} & \multicolumn{3}{|c|}{ Annual average efficiency [\%] } \\
\hline & & \multirow{2}{*}{$\begin{array}{l}\text { Electricity } \\
\text { production }\end{array}$} & \multicolumn{2}{|c|}{ Cogeneration } \\
\hline & & & Electricity & Heat \\
\hline \multirow{2}{*}{$\begin{array}{l}\text { Parabolic } \\
\text { trough system }\end{array}$} & No storage & 12.98 & 9.76 & 31.92 \\
\hline & $12 \mathrm{~h}$ storage & 14.32 & 11.11 & 30.73 \\
\hline \multirow{2}{*}{$\begin{array}{l}\text { Solar tower } \\
\text { system }\end{array}$} & No storage & 15.05 & 12.03 & 29.60 \\
\hline & $10 \mathrm{~h}$ storage & 15.65 & 12.80 & 26.92 \\
\hline
\end{tabular}

The availability and capacity factor of the heat production is also important. In case of a back pressure turbine the power and heat production occurs simultaneously, therefore the capacity factor data seen in the Table II are approximately applicable for the heat and power production in CHP mode. As a consequence, the thermal energy storage also improves the cogeneration features of CSP plants. A sufficiently large storage can enable the plant to be even the main heat supply of a process, supported by a reserve heat source only used at longer cloudy periods. However, when the storage is controlled for the purpose of meeting the heat demand, the power plant loses its biggest advantage, the dispatchability of electricity production. Consequently, the heat production of a CSP plant should only be used as complementary heat source, where the control is accomplished by the other heat producing device.

The biggest drawback of the cogeneration in CSP plants is the difficulty to find an appropriate heat demand. The peak heat production coincides with the peak of the solar irradiance, which usually occurs during summer, when the heat demand of district heating systems is typically very low. Absorption cooling is a possible technology for this purpose, because the demand for the highest cooling power is concurrent with the higher solar irradiance. Another possible application is seawater desalination, since the demand for a large amount of clear water also falls into the summer times, especially in case of water used irrigation systems. The combination of these technologies could be a renewable and environmentally friendly way to supply people living in remote, arid areas with electricity, heat, cooling power and clear water.

\section{Conclusion}

Model-based simulation analyses were performed for parabolic trough and solar power tower systems in order to discover the viability of the concentrating solar power technology. The results have shown that a CSP plant without storage produce electricity for a higher cost than the PV systems without any real advantage. Installing a high-capacity thermal storage not only significantly increases the capacity factor of the power plant, but also improves its average efficiency, which results in a much higher annual energy production and therefore in a better profitability. Furthermore, a CSP plant with sufficiently large storage can be considered as a dispatchable power generating unit, which can feed the electricity into the grid following a schedule, and is also able to take part in the frequency control of the grid. This dispatchability will be a very important advantage of the CSP plants in an energy system with a high share of weather dependent renewable energy sources. The extra revenues coming from this control capability can largely reduce the payback time of these plants in normal market conditions, although this benefit cannot be exploited with the nowadays common constant, subsidized feed-in tariffs.

The combined heat and power production is also a viable possibility in CSP plants. According to the simulation results high amount of heat can be produced using a back pressure turbine at the cost of a slight decrease in the electric power output. However, a huge drawback of the cogeneration is the typically low heat demand during the sunny when the solar irradiance and the heat production is high. In order to ensure the profitability the heat should be utilized in such applications where a high heat demand coincides with the production, like in case of absorption cooling or seawater desalination. The integration of such processes into a concentrating solar power plant could largely increase the profitability and the application area of the CSP technology.

\section{References}

[1] International Renewable Energy Agency: "Renewable Energy Technologies: Cost Analysis Series - Concentrating Solar Power". http://www.irena.org/

DocumentDownloads/Publications/RE_Technologies_Cost _Analysis-CSP.pdf, accessed 5 ${ }^{\text {th }}$ October, 2015.

[2] National Renewable Energy Laboratory: Concentrating Solar Power Projects. http://www.nrel.gov/csp/solarpaces, accessed $5^{\text {th }}$ October, 2015.

[3] M. J. Mayer, A. Dán, "Complex method for performance prediction of photovoltaic systems", International Conference on Renewable Energies and Power Quality 2014, Córdoba, Spain, $8^{\text {th }}$ to $10^{\text {th }}$ March, 2014.

[4] J. A. Duffie, W. A. Backman, "Solar Engineering of Thermal Processes", $2^{\text {nd }}$ edition, Wiley-Interscience, 1991.

[5] B. L. Kistler, "A User's Manual for DELSOL3: A Computer Code for Calculating the Optical Performance and Optimal System Design for Solar Thermal Central Receiver Plants", Sandia National Laboratories, 1986.

[6] A. M. Patnode, "Simulation and Performance Evaluation of Parabolic Trough Solar Power Plants", University of Wisconsin-Madison, 2006.

[7] Meteonorm: Irradiation database. http://meteonorm.com, accessed $10^{\text {th }}$ October, 2015. 